\title{
Effects of the time of the year and fire history on severity in the Serra Geral do Tocantins ecological station
}

\author{
Allan Deyvid Pereira da Silva ${ }^{1}$, Antonio Carlos Batista ${ }^{2}$, Marcos Giongo $^{3}$, Daniela Biondi Batista ${ }^{4}$, Jader \\ Nunes Cachoeira ${ }^{5}$, Micael Moreira Santos ${ }^{6}$ \\ 1,2, 4, ${ }^{5}$ Federal University of Paraná; ${ }^{3,6}$ Federal University of Tocantins \\ ${ }^{1}<$ allanuft@gmail.com>; ${ }^{2}<$ batistaufpr@gmail.com>; ${ }^{3}<$ giongo@mail.uft.edu.br>; \\ ${ }^{4}<$ danielabiondibatista@gmail.com>; ${ }^{5}$ jadernunes@mail.uft.edu.br>; ${ }^{6}<$ moreirasmicael@gmail.com>
}

\begin{abstract}
The prescribed burning is one of the most important actions within an extensive network of planning of ecological, cultural, socioeconomic and technical factors that are contemplated in the Integrated and Adaptive Fire Management. In a prescribed burning, it is always necessary to reduce fire severity levels to preserve or restore the ecological balance of the area. In this study, the objective was to determine the influence of the time without burning of the area and the time at which the burns are performed on levels of fire severity at the Serra Geral do Tocantins Ecological Station. Were realized prescribed burnings in May, June, August, and September 2017 and in areas for two, three and four years without burning. For assessing the severity of fire were applied two methods: the method of Minimum Diameter of Burned Branches-MDBB, consisting in taking the measurements of the diameter of carbonized branches of 10 Rourea Induta bushes distributed in each plot, for a total of 48 plots, in order to evaluate the capacity of the incident fire to consume the woody fuel branches of the bushes; and the visual assessment of the level of fuel consumption at the surface of the ground. According to the two methods employed, the fire severity levels were higher in the firings carried out in September and in areas that had not been burned for three and four years. The results showed that the fuel load from the third year without burning associated with intense drying of the fuel material after a long dry season (September), subjected to low air relative humidity levels, made the fire that affected the environment increase their capacity of consumption of plant biomass. Besides, the traditional knowledge disseminated in the region, which states that the fuel two years ago without burning does not present high fire severity, was confirmed in this study. The burnings of May, June, August, and September in the areas of two years showed average values between 0.10 and $0.16 \mathrm{~cm}$, being equal to each other $(\mathrm{p}<0.05)$ and lower than areas of three and four years burned in September, which presented 0.26 and $0.23 \mathrm{~cm}$ respectively.
\end{abstract}

Keywords: forest fires, prescribed burning, fire ecology. 